Olena Karagodina

Ukraine

Olha Baidarova

Ukraine

Viacheslav Fedchenkov

Ukraine

Iryna Pykalo

Ukraine

\title{
Needs in Social Workers' Training to Protect the Rights of Children
}

DOI: 10.15804/tner.2021.63.1.03

\begin{abstract}
The study aims to assess the professional training needs of employees of the two institutional actors for the protection of children's rights in Ukraine; identify factors shaping these needs. The data were obtained through an online survey of 452 people. Employees of two services differently assessed the importance of certain groups of competencies in their work that is related to the historic accounts of services' responsibilites. The needs in education are mostly correlated with the experience of workers in the implementation of difficult tasks that require knowledge and skills related to the fundamentals of work in the area of child protection, as well as competencies to establish rapport with families.
\end{abstract}

Key words: professional training, protection the rights of children, rights and interests of children, competences, educational needs.

\section{Introduction}

Protection of rights and interests of children is relevant for the social work (SW) throughout the world (Guerreiro \& Sedletzki, 2016; Gillingham, 2017; Dagan, Ben-Porat \& Itzhaky, 2015). In Ukraine, the system of social services has been functioning since the 1990-s. Today the Children's Affairs Service (CAS) and 
Centers of Social Services for Families, Children and Youth (SSFCY) are the main public institutions that protect the rights and interests of children. Within ongoing administrative reform, the delegation of children's social protection functions to the local communities is envisioned, thus the need for competent specialists of these services is especially acute (Slozanska, 2017).

The performance of social workers (SWs) in the area of children's rights protection is affected by the disparity between their education and practice requirements. Current curricula of higher education for social workers don't contain modules on ensuring children's rights or development of relevant competencies (Kubitskyi, 2017; Semigina, 2020). Specialists who protect the interests of children are not well aware of the provisions of the United Nations Convention on the Rights of the Child (Right to Protection, 2020). Professional development of the social service employees has been recognized as factors of efficient policy in the area of children's rights protection (Verkhovna Rada of Ukraine, 2018).

The aim of this research is to identify the needs in professional training of the employees of two main institutions involved in children rights protection - CAS and SSFCY and to identify reasons for these needs.

\section{Methodology of Research}

A group of Ukrainian national experts and practitioners have developed the model of basic professional competencies in the area of protection of rights and interests of children, which is aimed at development of a minimal level of knowledge and skills of the key institutional subjects in this area. This model is based on the educational and supportive approach to the development of competencies of professionals ensuring safety and wellbeing of children, introduced by the Institute for Human Services in Columbus, USA (Rycus \& Hughes, 2000). A working version of the basic competencies' model that contains 27 skills subdivided by 7 topic areas (groups or Gr) was developed on the first stage of project implementation (Table 1). They covered all key responsibilities and goals of the child protection services' workers.

Our study is based on the mixed methods design.

The survey participants included 1,256 workers of the CSSFCY, CAS and respective institutions of the amalgamated territorial communities. Out of them, 452 questionnaires (259, or $4.9 \%$ of the general population of the CSSFCY workers and 193 , or $4.8 \%$ of the general population of CAS workers) were selected using the method of multilevel cluster sample, which was developed on the basis of 
Table 1. Model of Basic Competencies of the Workers in the Area of Protection of Rights and Interests of Children

\begin{tabular}{ll}
\hline Gr1 & Basics of social work in child welfare and family support \\
\hline Gr2 & Ensuring child's development and wellbeing \\
\hline Gr3 & Building rapport with families to protect children \\
\hline Gr4 & Work with child maltreatment cases or threat of maltreatment \\
\hline Gr5 & Case management in child protection and family support \\
\hline Gr6 & Child advocacy \\
\hline Gr7 & Child removing and placement \\
\hline
\end{tabular}

parameters of the macro-regions of Ukraine, levels of service activities, administrative positions and professional areas of work of employees.

The questionnaire contained the attitudes scale to understand the attitude to the components of the proposed model of basic competences, open-ended questions to learn the previous professional experience of respondents and questions related to their social and demographic characteristics.

The first part of the questionnaire was aimed at identifying the training needs on the basis of answers about the importance of competencies, needs in their development and grasp of skills. There were three possible answers to the question Which of the competencies listed below are significant for your work?: a) it's important and I have it (1 score is added to the competence significance scale Sign and competence grasp Comp); b) it's significant but I want to develop it (1 score is added to the competence significance scale Sign and competence development Need); c) it's not significant (0 score). In this article the term 'need in training' is used as a cumulative relative indicator of three parameters: significance of a competence for the performance of service tasks; insufficient level of a competence; and the need to develop it. Answers to the first part of the survey were standardized with the use of a 10 -score scale.

The previous experience of respondents was analyzed on the basis of their answers to the open-ended questions. The semantic analysis was used to define the meaning of words and sentences. The previously designed model of basic competences of social area employees, who ensure protection of rights and best interests of children in Ukraine, was used as an operational blueprint of categories to encode the answers.

Quantitative data analysis methods included descriptive and inferential statistics. The Spearman's rank correlation coefficient for independent samples was 
used as an indicator of links between quantitative variables. Calculation of the 2-taile level of significance was made to interpret the directions of the identified differences. Analysis of variance (ANOVA) was used to assess the influence of independent variables (place of work and experience) on the dependent variables (significance of competencies, evaluation of grasp of competencies and needs in their development).

Factor analysis was used to single out the closely linked parameters of evaluation of competency significance. Kaiser-Meyer-Olkin Measure of Sampling Adequacy amounted to 0.835 , which indicated the high sampling adequacy. Bartlett's Test confirmed the possibility to perform the factor analysis $\left(\chi^{2}=1167.58\right.$; $\mathrm{df}=21$; $\mathrm{p}$ $<0.001)$. Factorization was performed with the Principal Component Analysis method followed by Rotation Method: Varimax with Kaiser Normalization. The reliability of differences in the need in training in relation to the professional experience was determined with the use of Chi-square criteria.

\section{Results of Research}

First, the answer to research question on the need to acquire basic competencies of a SWs who protects the rights of children related to the self-estimate of one's own professional competence was examined.

Mean values of the need to develop all three groups of competencies increase the value of indicators related to the level of grasp of these competencies, except

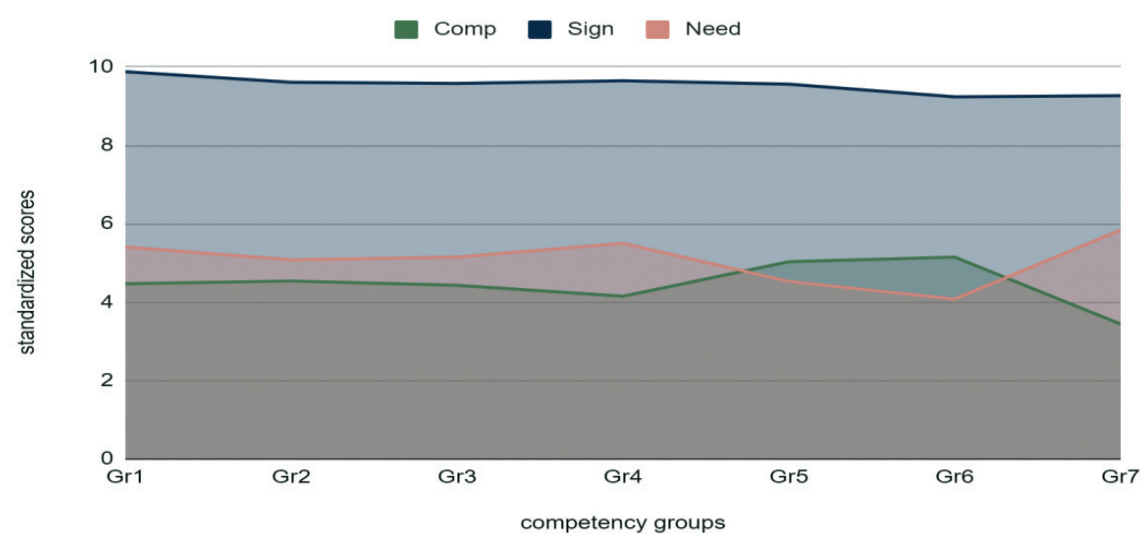

Fig. 1. Mean values of the respondents' $(\mathrm{N}=452)$ grasp of the groups of competencies (Comp), their significance (Sign) and need to develop them (Need) 
Table 2. Correlation matrix of the grasp of competencies and needs in their development

\begin{tabular}{|c|c|c|c|c|c|c|c|c|c|}
\hline & ea & $\begin{array}{l}\text { Std. } \\
\text { Dev. }\end{array}$ & $\begin{array}{c}\text { Comp } \\
\text { Gr1 }\end{array}$ & $\begin{array}{c}\text { Comp } \\
\text { Gr2 }\end{array}$ & $\begin{array}{c}\text { Comp } \\
\text { Gr3 }\end{array}$ & $\begin{array}{c}\text { Comp } \\
\text { Gr4 }\end{array}$ & $\begin{array}{c}\text { Comp } \\
\text { Gr5 }\end{array}$ & $\begin{array}{c}\text { Comp } \\
\text { Gr6 }\end{array}$ & $\begin{array}{c}\text { Comp } \\
\text { Gr7 }\end{array}$ \\
\hline Gr1 & 4 & 032 & $.981^{\star *}$ & $-0.557^{\star *}$ & $-0.567^{\star \star}$ & $-0.511^{\star *}$ & $-0.513^{\star *}$ & $-0.479^{* *}$ & $-0.539^{\star *}$ \\
\hline $\begin{array}{l}\text { Need- } \\
\text { Gr2 }\end{array}$ & 08 & 628 & $4 *$ & ** & -06 & -0.5 & ** & ** & $-0.454^{* *}$ \\
\hline Gr3 & 5 & 965 & 053 & -0.62 & -0.9 & -0.57 & -0.66 & $-0.497^{\star *}$ & -0.533 \\
\hline Gr 4 & 5 & 3.985 & $-0.480^{\star *}$ & $-0.533^{\star *}$ & $-0.548^{\star *}$ & $-0.929^{* *}$ & $-0.580^{\star *}$ & $-0.576^{\star *}$ & $-0.581^{\star *}$ \\
\hline $\begin{array}{l}\text { Need- } \\
\text { Gr5 }\end{array}$ & 4.53 & 3.976 & $-0.518^{\star *}$ & $-0.564^{\star *}$ & $-0.604^{\star *}$ & $-0.610^{* *}$ & $-0.924^{* *}$ & $-0.512^{\star *}$ & $-0.522^{\star *}$ \\
\hline Need- & .08 & 3.691 & $-0.446^{\star *}$ & $-0.395^{\star *}$ & $-0.455^{\star *}$ & $-0.537^{\star *}$ & $-0.492^{\star *}$ & $-0.877^{\star *}$ & $-0.577^{\star *}$ \\
\hline $\begin{array}{l}\text { eed- } \\
\text { r7 }\end{array}$ & .07 & 3.865 & $-0.483^{\star *}$ & $-0.391^{\star *}$ & $-0.478^{\star *}$ & $-0.531^{\star *}$ & $-0.452^{\star *}$ & $-0.518^{\star *}$ & $-0.856^{\star *}$ \\
\hline
\end{tabular}

Note: $\mathrm{N}=452 .{ }^{*}: \mathrm{p}<0.05,{ }^{* *}: \mathrm{p}<0.01$.

Gr5 and Gr6. The highest indicator of need to develop them was identified for Gr7. The data about the link between having competencies and an intention to further develop them are presented in Table 2.

So, there is a significant reverse correlation between the evaluation of the grasp of competencies and the need to further develop them $(\mathrm{P}<0.01)$.

Then, the self-estimation of the level of grasp of competencies depend on the area of the key functions performed in a certain organization was explored.

The Tests of Between-Subjects Effects were used to identify differences between the self-estimation of the level of grasp of competencies for the employees of CAS and CSSFCY in relation to the Gr2 of competencies 'healthy development and wellbeing of a child' $(\mathrm{F}(1,450)=13.803, \mathrm{p}<0.001), \mathrm{Gr} 3$ 'rapport with the family' $(\mathrm{F}(1,450)=4.310, \mathrm{p}=0.038), \operatorname{Gr} 5$ 'case management' $(\mathrm{F}(1,450)=20.790, \mathrm{p}<0.001)$, Gr6 'representation of interests' $(\mathrm{F}(1,450)=41.854, \mathrm{p}<0.001)$ and CompGr7 'removing and placement' $(\mathrm{F}(1,450)=14.573, \mathrm{p}<0.001)$.

The research was based on the presumption that performance of certain professional tasks determines the significance of certain skills needed for these tasks by the employee. The correlation analysis was used to test the presumed link between the level of grasp of competencies and significance of various groups of competencies (Table 3). 
Table 3. Correlation matrix of the grasp of groups of competencies and their significance for the performance of work tasks

\begin{tabular}{cccccccccc}
\hline & Mean & $\begin{array}{c}\text { Std. } \\
\text { Dev. }\end{array}$ & $\begin{array}{c}\text { Comp- } \\
\text { Gr1 }\end{array}$ & $\begin{array}{c}\text { Comp- } \\
\text { Gr2 }\end{array}$ & $\begin{array}{c}\text { Comp- } \\
\text { Gr3 }\end{array}$ & $\begin{array}{c}\text { Comp- } \\
\text { Gr4 }\end{array}$ & $\begin{array}{c}\text { Comp- } \\
\text { Gr5 }\end{array}$ & $\begin{array}{c}\text { Comp- } \\
\text { Gr6 }\end{array}$ & $\begin{array}{c}\text { Comp- } \\
\text { Gr7 }\end{array}$ \\
\hline $\begin{array}{c}\text { Sign- } \\
\text { Gr1 }\end{array}$ & 9.88 & 0.757 & 0.052 & 0.052 & 0.046 & -0.005 & 0.087 & -0.010 & 0.029 \\
\hline $\begin{array}{c}\text { Sign- } \\
\text { Gr2 }\end{array}$ & 9.61 & 1.54 & 0.026 & $0.164^{* *}$ & 0.067 & 0.064 & 0.057 & -0.035 & -0.013 \\
\hline $\begin{array}{c}\text { Sign- } \\
\text { Gr3 }\end{array}$ & 9.58 & 1.535 & $0.117^{*}$ & $0.136^{* *}$ & $0.160^{* *}$ & 0.069 & 0.079 & -0.022 & 0.040 \\
\hline $\begin{array}{c}\text { Sign- } \\
\text { Gr4 }\end{array}$ & 9.65 & 1.479 & 0.075 & $0.110^{*}$ & $0.133^{* *}$ & $0.133^{* *}$ & $0.129^{* *}$ & 0.039 & 0.049 \\
\hline $\begin{array}{c}\text { Sign- } \\
\text { Gr5 }\end{array}$ & 9.56 & 1.57 & 0.038 & $0.120^{*}$ & $0.115^{*}$ & 0.055 & $0.228^{* *}$ & 0.022 & 0.012 \\
\hline $\begin{array}{c}\text { Sign- } \\
\text { Gr6 }\end{array}$ & 9.24 & 1.88 & 0.076 & 0.072 & $0.109^{*}$ & $0.143^{* *}$ & 0.066 & $0.305^{* *}$ & $0.181^{* *}$ \\
\hline $\begin{array}{c}\text { Sign- } \\
\text { Gr7 }\end{array}$ & 9.27 & 1.949 & 0.086 & 0.073 & $0.113^{*}$ & $0.109^{*}$ & $0.122^{* *}$ & $0.219^{* *}$ & $0.211^{* *}$ \\
\hline
\end{tabular}

Note: $\mathrm{N}=452 .{ }^{*}: \mathrm{p}<0.05,{ }^{* *}: \mathrm{p}<0.01$.

A positive correlation $(\mathrm{p}<0.01)$ was identified between the significance of the groups of competencies and self-estimation of the level of their development for all corresponding groups of competencies except Gr1. Also, we see correlations between the significance of different groups of skills and competence. Work duties related to the removing and placement of children are related to the largest number of estimates of the grasp of groups of competencies.

According to the analysis of variance data, certain differences were identified in the significance of the following groups of competencies for the employees of CAS and CSSFCY: SignGr2 'healthy development and wellbeing of children' ( $F=$ $15.108, \mathrm{p}<0.001$, mean CAS 9.28, mean CSS 9.85), SignGr5 'case management' $(\mathrm{F}=17.110, \mathrm{p}<0.001$, mean CAS 9.21, mean CSS 9.82), SignGr6 'representation of interests' ( $\mathrm{F}=26.925, \mathrm{p}<0.001$, mean CAS 9.76, mean CSS 8.86), as well as SignGr3 'rapport with the family' $(\mathrm{F}=3.987, \mathrm{p}=0.046$, mean CAS 9.41, mean CSS 9.71).

The factor analysis was used to identify two main components (the aggregate explained variance $65.5 \%$ ), that determine the significance of a competence.

The first factor that explains $51.0 \%$ of variance include indictors SignGr1 'fundamentals of SW' (0.657), SignGr2 'healthy development and wellbeing of 
children' (0.802), SignGr3 'rapport with the family' (0.820), SignGr4 'work with child maltreatment cases' (0.743), SignGr5 'case management' (0.689). The second factor included the following indicators: SignGr6 'representation of interests' (0.886), SignGr7 'removing and placement' (0.823), which explain 14.5\% variance. The same factor included the indicator SignGr4 'work with child maltreatment cases. So, one can assert the presence of two obvious factors that determine the significance of certain competencies in the work of the researched SWs: FSignGr1 - general competencies needed to work with families; and FSignGr2 - competencies needed to work with children in need of protection.

An inverse correlation between these two factors $(\mathrm{r}=-0.498, \mathrm{p}<0.001)$ was identified for the general group of respondents. This correlation was also identified for subgroups of respondents by the place of work (for CSSFCY workers $r=-0.581$, $\mathrm{p}<0.001$, for CAS $\mathrm{r}=-0.306, \mathrm{p}<0.001$ ).

The respondents provided the following evaluation of different groups of working competences, specifying: a) skills related to the work with families, family strengthening to create a safe space for a child that meets its needs; and b) skills that are related to the protective function of a SWs in relation to a child (especially in cases where families are not able to care for children or even pose a threat to a child).

The study also looks into the question how the self-estimation of the level of competency development depends on the previous positive and/or negative professional experience.

The positive experience of workers is more frequently related to Gr5 'case management' (107 of respondents, 23.67\%) and Gr7 'removing and placement' (75 respondents, $16.59 \%$ ). Situations related to the Gr5 competencies were more frequently mentioned by the CSSFCY employees (79 respondents, $30.5 \%$ ), while the situations that required Gr7 competencies - by the CAC workers ( 55 respondents, $28.50 \%)$. The most complicated situations in the work of respondents were related to $\mathrm{Gr} 3$ competencies 'rapport with families' (171 respondents, 37.83\%).

Analysis of variance helped to identify the difference between the mean values of variables of self-estimation of the level of competencies by workers, whose previous experience demonstrated the sufficiency or deficiency of certain competencies. Differences were identified between the workers who had a positive experience of implementing professional tasks, in the self-estimates of Gr7 competence 'removing and placement' level $(\mathrm{F}=2.142, \mathrm{p}=0.031)$. Presumably, these differences are related to the place of work: only 20 or $7.7 \%$ of CSSFCY workers and much more (55 or $28.5 \%$ ) of CAS workers mentioned the successful implementation of professional tasks related to this group of competencies. 
Workers who have a negative experience in their professional duties demonstrated difference in the self-estimates of the level of competencies $\mathrm{Gr} 1(\mathrm{~F}=3.004$, $\mathrm{p}=0.003), \mathrm{Gr} 2(\mathrm{~F}=2.639, \mathrm{p}=0.008), \mathrm{Gr} 3(\mathrm{~F}=2.206, \mathrm{p}=0.026), \mathrm{Gr} 5(\mathrm{~F}=2.545$, $\mathrm{p}=0.010$ ). Among those who had difficulties with the performance of their professional duties related to the establishment of rapport with families, the highest difference was observed between the different services: - 121 workers of CSSFCY (46.7\%) and 50 workers of CAS (25.9\%).

The previous positive or negative professional experience did not influence the self-estimation of the level of development of the following competencies: Gr4 'work with child maltreatment cases' $(\mathrm{F}=1.443, \mathrm{p}=0.176)$, Gr6 'representation of interests' $(\mathrm{F}=1.330, \mathrm{p}=0.226)$ and $\mathrm{Gr} 7$ 'removing and placement' $(\mathrm{F}=1.928$, $\mathrm{p}=0.054)$.

Comparing the results of answers to the open-ended question about the professional experience with the answers to the question about self-estimates of competencies in the area of child protection with the use of $\chi^{2}$ criterion turned out to be insufficiently reliable, because part of the cells in the tables of correlation with expected count less than 5 exceeded $20 \%$ for the majority of identified differences. A reliable correlation of the deficient experience with the self-estimated level of competencies was identified only for Grl 'fundamentals of work' $\left(\chi^{2}=40.792, \mathrm{p}=\right.$ $0.018)$ and Gr3 'rapport with family' $\left(\chi^{2}=51.368, \mathrm{p}=0.001\right)$.

A reliable correlation of needs in competency development with the previous professional experience was identified for several groups of competencies, the deficiency of which was felt by the workers while performing their professional duties. The negative experience of workers was related to their estimate of need to develop competencies Gr1 $\left(\chi^{2}=45.499, \mathrm{p}=0.005\right)$, Gr3 $\left(\chi^{2}=40.493, \mathrm{p}=0.019\right)$ and $\operatorname{Gr} 6\left(\chi^{2}=38.003, \mathrm{p}=0.034\right)$.

The estimates of competences and needs in education are mostly correlated with the experience of workers in the implementation of difficult tasks that require knowledge and skills related to the fundamentals of work in the area of child protection, as well as competencies to establish rapport with families.

\section{Discussion}

Differences observed during the study among the workers of two institutions clearly charachetized the Ukrainian system of children's rights protection: the narrow functional focus of different organizations, sectoral division and rigidity to changes. For a long time the CSSFCY and CAS employees used different basic 
principles in their work and it hindered integration of their contributions in the work with families and work to protect the rights of children. Today the CSSFCY workers are responsible for the identification of families and children in difficult living conditions and for the organization of social, health, psychological and other support to them, including protection of their physical and mental health. The CAS employees are responsible for the control over the observance of the rights of children in difficult living conditions and for the social and legal protection of such children, especially orphans and those deprived of parental care. Thus, the CAS workers estimate the skills that envisage a direct interaction with a child and its family as less significant, although such approach doesn't meet the principles of the family-centered SW.

The data about the respondents' self-estimation of their skills to perform function related to the representation of interests, removing and placement children in the family can be used to establish cooperation between the workers of different services. While developing educational curricula there is a need to foresee the variety of the amount and content of the educational materials on the development of such competencies among the representatives of both institutions. Topics on basics of social work in child welfare and family support, as well as on work with child maltreatment cases or threat of maltreatment could be delivered equally to all participants. A similar priority of educational topics was noticed by other researches (Dimitrova, 2017).

This research had partially confirmed the hypothesis that there is the link between the need to develop competencies and the experience of situations where such competencies were lacking. The complexity of tasks is linked to the 'nuclear' competencies of SW with families and children: (a) understanding the fundamental values and an ability to apply the principles of work; understanding the system of child protection, and (b) establishing rapport with families, their engagement and development of cooperation. Possibly, it is the outcome of the lack of basic education in SW among the majority of respondents.

Our findings are in line with ideas that family engagements serve as a key factor of successful child protection activities (Drake, 1994), while the ability of a practitioner to establish efficient working relationships is a prerequisite for the intervention effectiveness (Horwitz \& Marshall, 2015). Research findings also confirm the challenges in overcoming the discrepancy between the experience and understanding of one's needs in training. The supervision could be an asset for that (Caras \& Sandu, 2014). However, in Ukraine this area of professional activity is limited (Karagodina \& Baidarova, 2014). Identification of this aspect of training may become a subject of an additional research with the application of qualitative method. 


\section{Conclusions}

Competency-based approach to professional training is a relatively new trend both for the social work education inUkraine, and for the evaluation of human capacity of service providers.

This research indicates the lack of direct correlation between the professional experience and awareness of the competency level, the authors actually illustrated the lack of one of the most important professional qualities of SWs - ability to have a professional reflection. Without a proper education and experience of supervision, workers in the area of protection of rights and interests of children are not able to evaluate the significance of their own professional tasks against current standards of SW.

The professional programmes for the practitioners in the area of child protection are acquiring a new content. There is a need to overcome the lack of a 'basic understanding' of the essence of this profession by all key subjects working in the area of protection of the rights and interests of children, and at the same time to consolidate the professional community taking into account uniform understanding of the essence of this profession.

\section{References}

Caras, A. \& Sandu, A. (2014). The Role of Supervision in Professional Development of Social Work Specialists. Journal of Social Work Practice, 28(1), 75-94. doi: 10.1080/02650533.2012.763024

Dagan, S., Ben-Porat, A., \& Itzhaky, H. (2015). Child protection workers dealing with child abuse: The contribution of personal, social and organizational resources to secondary traumatization. Child Abuse and Neglect, 51, 203-211.

Dimitrova, P. (2017). Study on the Needs of Continuing Vocational Training for Social Workers in Bulgaria. Journal of Innovations and Sustainability, 3(2), 9-29.

Drake, B. (1994). Relationship Competencies in Child Welfare Services. Social Work, 39(5), 595-602. doi: 10.1093/sw/39.5.595

Gillingham, P. (2017). Evaluation of practice frameworks for social work with children and families: exploring the challenges. Journal of Public Child Welfare, 12(2), 190-203. doi: $10.1080 / 15548732.2017 .1392391$

Guerreiro, A.I.F., \& Sedletzki, V. (2016). Children's rights and social services. Report on the implementation of the Council of Europe Recommendation on children's rights and social services friendly to children and families. Retrieved from https://rm.coe.int/1680649301.

Horwitz, M., \& Marshall, T. (2015). Family Engagement in Child Protection Social Work. Journal of Family Social Work, 18(4), 288-301. doi: 10.1080/10522158.2015.1079584

Karagodina, O., \& Baidarova, O. (2014). Superwizja pracy socjalnej na Ukrainie [Social 
Work Supervision in Ukraine]. Superwizja pracy socjalnej, Wyz'sza Szkola Pedagogiczna im. Janusza Korczaka w Warszawi, Centrum Wspierania Aktywnos'ci Lokalnej CAL, Warszawa, 102-109.

Kubitskyi, S.O. (2017). Analysis of educational and professional training programs for specialists in the specialty 231 Social work. ScienceRise. Pedagogical Education, 6, 18-22. doi: $10.15587 / 2519-4984.2017 .105503$

Right to Protection (2020). Alternative report on Ukraine's compliance with the provisions of the UN Convention on the Rights of the Child for the period from 2011 to 2020. Retrieved from https://r2p.org.ua/wp-content/uploads/2020/06/alternative-report.pdf . Rycus, J.S., \& Hughes, R.C. (2000). What is Competency-Based Inservice Training? Columbus, $\mathrm{OH}$ : Institute for Human Services. Retrieved from https://www.researchgate.net/ publication/240623466.

Semigina, T. (2020). Arrangement of the social work students' field education: the experience of Ukraine. Pedagogical concept and its features, social work and linguology. Dallas: Primedia eLaunch LLS. doi: 10.36074/pcaifswal.ed-1.03

Slozanska, H. (2017). Social services: are current state social agencies ready to provide them on the level of local communities in Ukraine (selective survey). Social work and education, 2(4), 77-101.

Verkhovna Rada of Ukraine (2018). Annual report of the Ukrainian Parliament Commissioner for Human Rights on the observance and protection of the human rights and freedoms of citizens of Ukraine. Retrieved from http://www.ombudsman.gov.ua/en/ page/secretariat/docs/presentations/. 